\title{
Group Performance in Information Systems Project Groups: An Empirical Study
}

The authors acknowledge the research grant provided by the John Molson School of Business at Concordia University to support this study

\section{Bouchaib Bahli and Meral Demirbağ Büyükkurt John Molson School of Business, Concordia University Montreal, Quebec, Canada}

\section{bbahli@jmsb.concordia.ca mbuyukkurt@jmsb.concordia.ca}

\section{Executive Summary}

The importance of teamwork in Information Systems Development (ISD) practice and education has been acknowledged but not studied extensively to date. This paper tests a model of how groups participating in ISD projects perform and examines the relationships between some antecedents of this performance based on group research theory well established in the organizational behavior literature.

Most modern organizations require individuals to work in teams to perform their tasks. Information systems development teams, advertising teams, and new product development teams are only a few examples from the business community. The group work environment creates challenges for the group members that may affect the group's performance. The relevance and importance of group performance and its antecedents has been addressed in other areas of research: in Social Cognitive Theory (Bandura, 1997), and group related research theories (Festinger, Schachter, \& Back, 1950; Gibson, 1999; Salas, Rozell, Mullen, \& Driskell, 1999; Woodman \& Sherwood, 1980). The importance of group work is also recognized within IS practice (Gorla \& Lam, 2004; Sawyer, 2004) and IS education (Ford \& Morice 2003; Gackowski, 2003; Whatley, 2004) as organizations look for ways to improve group performance (Lee \& Farh, 2004; Trimmer, 1997; Van Der Vyer \& Lane, 2003). For example, organizations are looking for products, such as groupware software and web portals, that allow for online collaborative work, in turn helping them to think more quickly, to reduce production costs, and to get those products to the market sooner. Another example are IS projects that involve group work is Information Systems Development (ISD) which often involve systems analysts and designers working in a group setting, either face-to-face or through electronic collaboration. As a result, organizations need to have an in-depth understanding of what encourages groups to perform better (Phan, Vogel, \& Nunamaker, 1995; Yang $\&$ Tang, 2004) regardless of the medium of communication. Moreover, Alavi, Wheeler, and

Material published as part of this journal, either on-line or in print, is copyrighted by the publisher of the Journal of Information Technology Education. Permission to make digital or paper copy of part or all of these works for personal or classroom use is granted without fee provided that the copies are not made or distributed for profit or commercial advantage AND that copies 1) bear this notice in full and 2) give the full citation on the first page. It is permissible to abstract these works so long as credit is given. To copy in all other cases or to republish or to post on a server or to redistribute to lists requires specific permission and payment of a fee. Contact Editor@JITE.org to request redistribution permission.
Valacich (1995) suggest that this issue needs to be incorporated into IS and business education.

Therefore, the goal of this study is to identify, define and measure the determinants of group performance in ISD projects. To meet this need, a comprehensive research model is developed based on small-group research and IS literature. First, this 
research reviews the theoretical foundations upon which it is built. We, then, discuss the research model and hypotheses, and describe the research methodology. Finally, we present the results and discuss the practical and research implications of these results. The results suggest that team building has a positive effect on both task and social cohesion. Group performance is influenced by task cohesion. Our findings make several contributions to information systems literature. First, our findings extend the existing literature on group research by exploring the process by which group performance is realized. Second, they demonstrate the applicability of small-group research to information systems development groups. Thirdly, they provide insights for researchers and practitioners to enhance their understanding of various determinants of group performance. Finally, our findings are useful to educators in (ISD) field who incorporate group work into their course design.

Keywords: System Development, Group Performance, Group Cohesion, and Team Building.

\section{Background}

A review of the literature on group research indicates that group performance is influenced by the following constructs: team building (Hardy \& Crace, 1997), and group cohesion consisting of task and social cohesion (Chang \& Bordia, 2001). In this study, we attempt to develop and test the relationships between these constructs in one comprehensive model so that we can understand the underlying determinants of group performance.

\section{Group Performance}

Group performance has been conceptualized in terms of objective and subjective outcomes. Objective assessment includes quantifiable measures, such as group productivity, whereas subjective measures include the subjective ratings of group performance. Hackman (1990) identifies three dimensions of the group-performance construct: first, task effectiveness, which refers to the degree to which group output meets the standards of the organization; second, system viability, which refers to the degree to which the process of carrying out the work enhances the capability of members to work together interdependently in the future; finally, professional growth, which refers to the degree to which the group experience contributes to the growth and personal wellbeing of team members. To date, and to the best of our knowledge, only one study (Chang \& Bordia, 2001) has tested this measure of group performance empirically. However, the importance of assessing this construct is critical, since it is the dependent variable in most group-related studies.

\section{Group Cohesion}

Conceptualization and measurement of group cohesion dates back to Festinger et al. (1950), who defined group cohesion as "the total field of forces which act on members to remain in the group. These forces may depend on the attractiveness or unattractiveness of either the prestige of the group, members of the group, or the activities in which the group engages" (p. 274). The importance of this construct has been indicated as the key to effective work groups in a number of studies (Carless \& De Paola, 2000; Cohen \& Bailey, 1997; Forsyth; 1990; Yang \& Tang, 2004). More importantly, conceptualization and measurement of group cohesion has been based on models with a variety of factor structures. Mullen \& Copper (1994) tested a construct with a one-factor structure, namely interpersonal attraction to the group. In their conceptualization of group cohesion as a two-factor model, Widmeyer, Brawley, and Carron (1985) distinguished between individual attraction to the group and group integration. More recently, Cota, Evans, Dion, Kilik, and Longman (1995) defined group cohesion as a multidimensional construct based on the Group En- 
vironment Questionnaire (GEQ) developed for sports groups by Widmeyer et al. (1985). According to Cota et al. (1995) group cohesion has four dimensions: (1) Group Integration-Task, (2) Group Integration-Social, (3) Individual Attraction to Group-Task, and (4) Individual Attraction to Group-Social. Group Integration-Task is defined as an individual team member's perception of the similarity and closeness within the team in accomplishing the task, whereas Group Integration-Social reflects an individual team member's perception of closeness and bonding regarding the team's social activities. Individual Attraction to Group-Task describes an individual team member's feeling about personal involvement in the group task, whereas Individual Attraction to Group-Social reflects an individual team member's feeling about personal involvement in the social interaction of the group.

More recent studies, such as Carless and De Paola (2000), introduced the concept of separating task and social cohesion when defining group cohesion. They tested the group cohesion construct as (1) a single-factor model, defining cohesion as highly interrelated perceptions of the group; (2) a two-factor model based on Widmeyer et al. (1985); (3) a two-factor model based on task and social cohesion; and (4) a four-factor model based on the Cota et al. (1995) model. The authors concluded that the group cohesion construct is multidimensional and includes task cohesion -- the extent of motivation towards achieving the organization's goals and objectives, and social cohesion, -- the motivation to develop and maintain social relationships within the group. In addition, group cohesion appears to influence performance (Klein \& Mulvey, 1995; Podsakoff, MacKenzie, \& Ahearne, 1997; Spink \& Carron, 1993). Groups that show a high degree of cohesion in terms of task completion and social attractiveness achieve greater performance. However, there is no conclusive result of group research either in IS or in small-group research literature. Recently, Yoo and Alavi (2001) found that task participation played a more important role than social presence in determining the degree of consensus among group members in computermediated communication environments. This result demonstrates that there is a positive correlation between task-oriented groups and high performance, however there is presently no evidence that social attractiveness and participation has either a positive or a negative effect on performance. This study attempts to test and validate this claim.

\section{Team Building}

Salas et al. (1999) have defined team building as "enlisting the participation of a group in planning and implementing change which will be more effective than simply imposing change on the group from outside". Cohen \& Bailey's (1997) definition is "A team is a collection of individuals who are interdependent in their tasks, who share responsibility for outcomes, who see themselves and who are seen by others as an intact social entity embedded in one or more larger social systems, and who manage their relationship across organizational boundaries". Powell, Piccolo, \& Ives (2004) refer to teams as "groups that display high levels of interdependency and integration among members". The extensive literature review conducted on team building and its application to sports groups by Hardy and Crace (1997) proved that team building leads to an increase in team performance. On the other hand, Smither, Houston, and McIntire (1996) stated that research findings on the effectiveness of team building provided mixed results making firm conclusions difficult. The reasons behind these findings can be attributed to the non-empirical, narrative nature of most of these studies and the ambiguity of what team building is.

Indeed, team-building conceptualization in the business context dates back to Beer (1976) who attempted to formalize this construct. Salas et al. (1999) built on Beer's (1976) work and identified four components of team building. The first was goal setting, where group members set objectives at the beginning of the task. The second was interpersonal relations, where group members develop trust in one another and confidence in the group. The third was problem solving, where group members become involved in finding solutions to the problems encountered. The 
final component was role clarification, where there is increased communication among group members regarding their roles within the group.

Since the current research involves an IS context, it is necessary to review literature on teams within the IS field. Jiang, Klein, and Discenza (2000) have defined teams as having members bonding through the development of a common set of project goals and objectives. The team establishes a set of procedures for resolving conflict during the course of the project's completion, thus building a team, and this has a positive effect on the project outcomes. In addition, by examining team building or team development in self-directed work groups, Janz (1999) found that team members who have a clear mission work in harmony and unity in an efficient way.

A summary of literature on team building, group cohesion, and group performance is presented in Table 1.

Table 1: Summary of empirical research on group performance and its determinants

\begin{tabular}{|c|c|c|c|}
\hline Author and Year & $\begin{array}{l}\text { Team } \\
\text { Building }\end{array}$ & $\begin{array}{l}\text { Group } \\
\text { Cohesion }\end{array}$ & $\begin{array}{l}\text { Group } \\
\text { Performance }\end{array}$ \\
\hline (Earley, 1994) & & & $\mathrm{X}$ \\
\hline (Gibson, Randel, \& Earley, 2000) & & & $\mathrm{X}$ \\
\hline (Gibson, 1999) & & & $\mathrm{X}$ \\
\hline (Pescosolido, 2001) & & & $X$ \\
\hline $\begin{array}{l}\text { (Peterson, Mitchell, Thompson, \& } \\
\text { Burr, 1996) }\end{array}$ & & & $\mathrm{X}$ \\
\hline (Shea \& Guzzo, 1987) & & & $X$ \\
\hline (Silver \& Bufiano, 1996) & & & $\mathrm{X}$ \\
\hline (Spink, 1990) & & & $\mathrm{X}$ \\
\hline (Hardy \& Crace, 1997) & $\mathrm{X}$ & & $\mathrm{X}$ \\
\hline$($ Janz, 1999) & $\mathrm{X}$ & & $\mathrm{X}$ \\
\hline (Jiang et al., 2000) & $\mathrm{X}$ & & $\mathrm{X}$ \\
\hline (Salas et al., 1999) & $\mathrm{X}$ & & $\mathrm{X}$ \\
\hline (Shandler \& Egan, 1996) & $\mathrm{X}$ & & $\mathrm{X}$ \\
\hline (Woodman \& Sherwood, 1980) & $\mathrm{X}$ & & $\mathrm{X}$ \\
\hline (Yang \& Tang, 2004) & & $\mathrm{X}$ & $\mathrm{X}$ \\
\hline (Carless \& De Paola, 2000) & & $\mathrm{X}$ & $\mathrm{X}$ \\
\hline (Chang \& Bordia, 2001) & & $\mathrm{X}$ & $\mathrm{X}$ \\
\hline
\end{tabular}




\begin{tabular}{|lll}
\hline (Cohen \& Bailey, 1997) & X & X \\
(Klein \& Mulvey, 1995) & X & X \\
(Podsakoff et al., 1997) & X & X \\
(Spink \& Carron, 1993) & X & X
\end{tabular}

\section{Research Model and Hypotheses}

As can be seen in Table 1, prior research reflects studies that have investigated relationships between one dependent variable (i.e., group performance) and one independent variable (i.e. team building or group cohesion) at a time. We recognize that besides team building and group cohesion, there are other constructs that determine group performance (i.e. group efficacy, conflict). This study aims to develop and test a comprehensive structural model of group performance, as shown in Figure 1, that illustrates the most commonly used constructs (group cohesion and team building). Cohen and Bailey (1997) have called for this type of comprehensive research model to capture how group performance is achieved. Accordingly clear conceptualisation of the constructs and assessment of their reliability and validity within a nomological model is highly recommended (Carmines \& Zeller, 1979). In addition, this study perceives task cohesion and social cohesion as two distinct constructs. Prior research combined both constructs into one (i.e. group cohesion) and found mixed results regarding its antecedents and consequences (Carless \& De Paola, 2000). We believe that this distinction is necessary for two reasons. First, by aggregating the items of cohesion construct, it is difficult to identify which part of the cohesion is really related to group performance. Second, group members who are collectively task-oriented may not be socially oriented, and vice versa. We therefore propose the following research model.

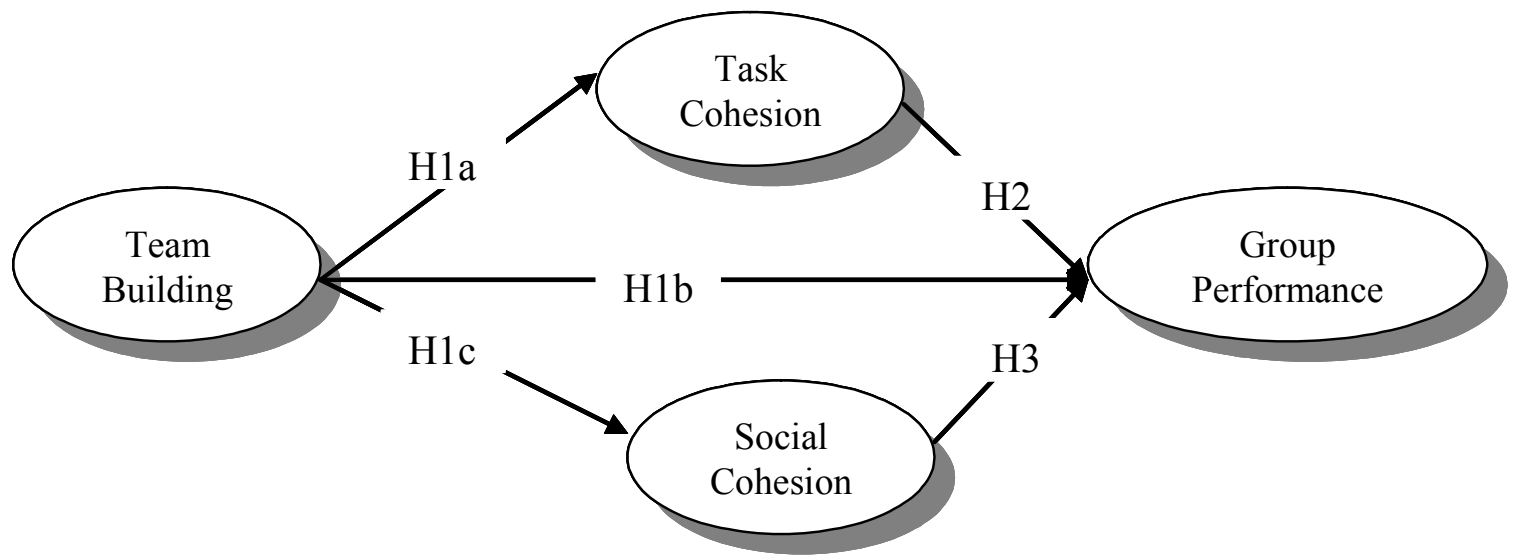

Figure 1: Research model.

Woodman and Sherwood (1980) have observed that there is no conclusive evidence that team building renders an increase in team performance. Furthermore, Salas et al. (1999) have suggested that a clear summary of the effects of team building on performance apparently cannot be formulated from narrative literature reviews conducted within the past two decades. The judgments rendered by these review efforts have been inconclusive. The process by which groups de- 
velop will result in group members developing a certain degree of cohesion both task and social (Forsyth, 1990). Since previous research could determine and assert this observation, it is useful to consider group cohesion as an intermediary construct between team building and group performance. To verify and test this link between team building and its effects on performance and task and social cohesion, we hypothesize that:

H1a: Team building is positively related to task cohesion

H1c: Team building is positively related to social cohesion

H1b: Team building is positively related to group performance

Task and social cohesion, and their impact on group performance, have been a subject of interest in several models of effective groups (Carless \& De Paola, 2000; Chang \& Bordia, 2001; Cohen \& Bailey, 1997; Klein \& Mulvey, 1995; Podsakoff et al., 1997; Spink \& Carron, 1993). The importance of these constructs has been identified as a crucial element in effective work groups (Chang \& Bordia, 2001). Accordingly, it is expected that IS project team members who show a high level of cohesion will perform better. To our knowledge, none of the studies examined this effect separately at the task and social levels. When the items of the cohesion construct are aggregated, it is difficult to identify which part of the cohesion is really related to group performance. Accordingly, this study attempts to differentiate these two constructs and test the link between them and group performance. Moreover, prior research has tested only the relationship between group cohesion and group performance. Since we build a nomological model that shows both the antecedents and consequences of task and social cohesion, it would seem that the relationship between group cohesion and group performance as tested before should hold. Hence, we hypothesize that:

$\mathrm{H} 2$ : Task cohesion is positively related to group performance.

H3: Social cohesion is positively related to group performance.

\section{Method}

\section{Sample of Respondents}

One hundred and eighty-five undergraduate students majoring in MIS and enrolled in a fourthyear systems analysis course participated in the study. While participation in the study was voluntary, all the students chose to participate. The participants included $81(47 \%)$ females, and 92 $(53 \%)$ males. Their ages ranged between 19 and 40, with an average age of 24 . While most of them $(81 \%)$ had student experience working in groups, slightly more than half of them $(54 \%)$ also had professional experience working in groups. Thirty-five groups of four to six students were formed randomly at the beginning of the semester. Since the groups were formed randomly there were no groups that had prior experience of working together.

The groups worked as consultants on system analysis projects for different companies in a metropolitan city in Canada. First, each team contacted companies and offered their services as systems analysts. They then submitted a proposal to their professor for a systems analysis project for two potential clients. The professor made the final decision on the clients to be selected and the scope of the projects, making sure that projects across groups were of comparable scope. The projects were initiated with the proposal in the second week of the semester, and continued for 12 weeks. Throughout the semester, the professor supervised the projects, met several times with each team, and guided them in dealing with any challenges they might face. The professor was especially careful to provide comparable amount and type of help to all the teams during office hours that each group was required to attend 
The projects ended with a written report submitted to the client and the professor and a presentation given to the class, the professor, and to the clients who wished to attend. The professor evaluated each project, based on the written report and the oral presentation. Members of each team also evaluated other member's contribution to the project. The students were instructed and encouraged to evaluate each other fairly. While the average of the peer evaluations each student received constituted the percentage of his/her final project grade, any extreme evaluations were further investigated by the professor to ensure fairness and to avoid possible collusion among members of a team. On the average the participants perceived their groups to be productive, to have worked well together, and that the quality of the group work was very good. Data was collected at the end of semester after the completion of the project and before the evaluation of the project and filing the grades. Participants in the study were informed that the research was intended for no other purpose than to have a better understanding of group dynamics and their effect on group performance. They were also informed that all data would be kept anonymous.

\section{Questionnaire Items}

Following Churchill's (1979) suggestions for developing instruments with desirable psychometric properties, literature on group research, as well as IS literature, were surveyed before the questionnaire used in data collection was developed. The conceptual definitions of the constructs were examined and the dimensions identified were verified. The items of the construct that captured the domain of the construct and had high reliability scores were selected. The number of items for each of the constructs ranged from one to four. Task cohesion and social cohesion were each measured by four-item scales in accordance with Chang and Bordia (2001). A four-item scale that assessed goal setting, interpersonal relations, problem solving, and role clarification (Salas et al., 1999) measured team building. A three-item subjective scale assessing the perceived quality and productivity of the group (Hackman, 1990) measured group performance. In addition, an objective measure (group project grades) of group performance was used. A list of the constructs and the scales is presented in Table 2.

Table 2: Questionnaire items

\begin{tabular}{||l|l|l||}
\hline Constructs & Items & $\begin{array}{l}\text { Refer- } \\
\text { ences }\end{array}$ \\
\hline Task Cohesion & $\begin{array}{l}\text { Our group was united in trying to reach its goals for perform- } \\
\text { ance. } \\
\text { I was very happy with my group's level of commitment to the } \\
\text { task. } \\
\text { We did not have a lot of conflicting aspirations for the group's } \\
\text { performance. } \\
\text { This group gave me enough opportunities to improve my per- } \\
\text { sonal performance. }\end{array}$ & $\begin{array}{l}\text { Our group spent a lot of time together outside of hours spent } \\
\text { on group project. } \\
\text { Secial Cohesion } \\
\text { Paola, } \\
\text { 2000) }\end{array}$ \\
$\begin{array}{ll}\text { time. } \\
\text { Our group members partied together. } \\
\text { Members of our group would rather get together as a group } \\
\text { than go out on their own. }\end{array}$ & \\
\hline
\end{tabular}




\begin{tabular}{|c|l|l|}
\hline \multirow{5}{*}{ Team Building } & $\begin{array}{l}\text { We set objectives to achieve both individual and group goals. } \\
\text { There was a mutual supportiveness, communication, and } \\
\text { sharing of feelings among group members. } \\
\text { We were involved in the identification of major problems in } \\
\text { the group and implementing solutions for those problems. } \\
\text { There was a lot of communication among group members } \\
\text { regarding their respective roles within the group. }\end{array}$ & $\begin{array}{l}\text { (Salas et } \\
\text { al., 1999) }\end{array}$ \\
$\begin{array}{c}\text { Group } \\
\text { Performance }\end{array}$ & $\begin{array}{l}\text { Our group was very productive. } \\
\text { We worked very well as a group. } \\
\text { The quality of our group work is very good. }\end{array}$ & $\begin{array}{l}\text { (Hack- } \\
\text { man, } \\
1990)\end{array}$ \\
\hline
\end{tabular}

\section{Analytical Procedures}

A pre-test was performed to check the wordiness and clarity of the questionnaire according to Churchill's (1979) suggestions. Hair, Anderson, Tatham, \& Black, (1998) have underlined the importance of screening data prior to any analysis. The first screening was performed based on missing data. Out of the 185 questionnaires completed, 12 were removed from further analysis because they were only partially completed. Since the percentage of cases removed is only $6.5 \%$, it is fairly acceptable to remove them from rather than utilize more sophisticated imputations to estimate the missing values (Schafer, 2000, p. 1). The investigation of issues related to missing data, outliers and assumptions of multivariate analysis followed Hair et al.'s (1998) guidelines. Screening the 173 usable questionnaires for missing data showed only 9 out of 173 cases $(5.2 \%)$ were missing only one data item each. Since the percentage of missing data was so low, a simple method such mean substitution was used to generate the replacement values rather than a more sophisticated method such as multiple imputations (Hair et al., 1998; Schafer, 2000). Furthermore, univariate and multivariate outliers (unusual observations that may not be representative of the population under study) were examined, since they have the potential to seriously distort statistical tests. Since most of the variables under study were measured on a seven-point scale, and none of the observations appeared to be extreme, all the data were kept for analysis. Furthermore, data normality was checked even though it is not a requirement of Partial Least Squares (PLS) method. Skewness and Kurtosis tests in addition to the Kolmogorov-Smirnov normality test were used for this purpose. The result of this examination strongly supports data normality assumption.

\section{Results}

\section{Assessment of the Measurement Model}

Assessment of the research model was performed using self-reported survey data and PLS approach to multiple indicator structural equation analysis. The largest construct in this study has four items, which makes a required sample by PLS of 20 observations (4 x 5). The sample consists of 35 observations (groups). Although it is based on ordinary least-squares regression, PLS was chosen over regression because it: 1) allows for the modeling of multiple dependent and independent variables; 2) incorporates unobservable constructs, and 3) empirically estimates the contribution of multiple construct measures. In addition, PLS was suitable for this study since the research model is at the early stage of development. To the best of our knowledge, this is the first 
study that examines group cohesion in terms of both task and social cohesion as a process through which team building affects group performance.

PLS analysis involves two steps: (1) assessment of the measurement model, including the reliability and discriminant validity of the measures, and (2) assessment of the structural model. For the assessment of the measurement model, individual item loadings and internal consistency reliabilities were examined as a test of reliability. For discriminant validity, items should load higher on their own construct than on the other constructs in the model, and the average variance shared between the constructs and their measures should be greater than the variances shared between the constructs themselves. The structural model and hypotheses were tested by examining the path coefficients. In addition, the explained variance in the dependent constructs was assessed as an indication of model fit. Table 3 shows the correlation matrix.

In the following three sections, we present both the measurement and the structural models. We first tested the reliability and validity of our constructs and kept only the measures that showed high reliability and validity for further testing.

\section{Table 3: Correlation matrix}

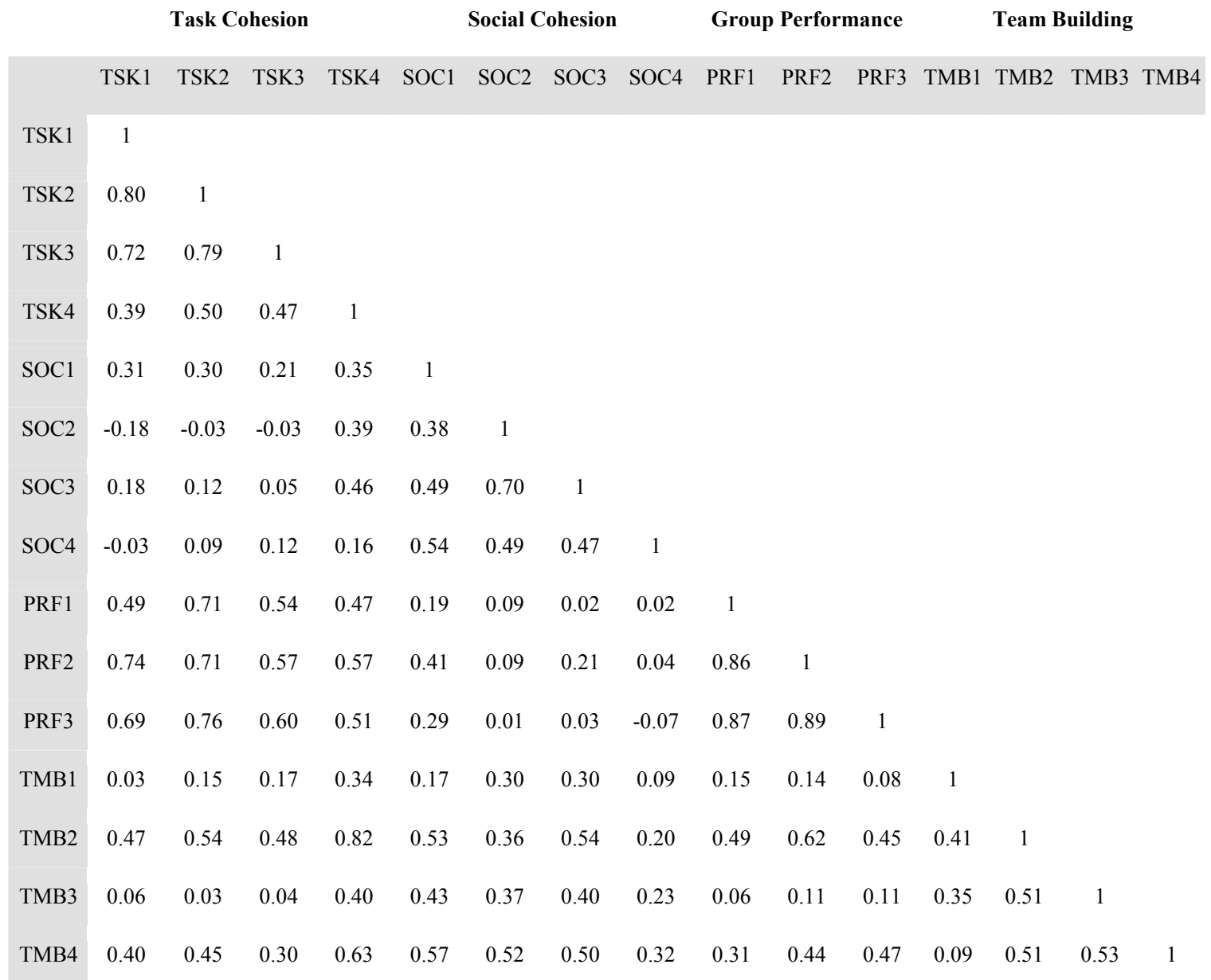

\section{Reliability Assessment}

PLS estimates the parameters for both the links between measures and constructs (i.e. loadings) and the links between different constructs (i.e. path coefficients) at the same time. The adequacy of the measurement model can be assessed by looking at: (1) the convergent validity of the meas- 
ures associated with individual constructs (2) individual item reliabilities, and (3) discriminant validity. Reliability of constructs is assessed by using the Cronbach's alpha, which reflects the consistency of the measure and the homogeneity of the items in the scale. Cronbach's alphas for all the variables displayed in Table 4 exceeded 0.70, the benchmark Nunnally established for instruments used in exploratory research (Nunnally, 1978).

Reliabilities of individual items are assessed by examining the loadings of the items on their respective constructs. Loadings higher than 0.5 indicate that significant variance is shared between each item and the construct (Rivard \& Huff, 1988). Since the loadings of each item on its corresponding construct displayed in Table 5 is above 0.7 , the first test of reliability is positively assessed.

The third indicator assessed is the Rho coefficient, which is a measure of internal consistency. It is assessed in a PLS model using a measure developed by Fornell and Larcker (1981). Unlike Cronbach's alpha, the number of items in the scale does not influence the Rho coefficient. It is however, influenced by the relative loadings of the items. The Rho coefficient is based on the ratio of construct variance to the sum of construct and error variance, a value greater than .50 indicating that the construct variance accounts for at least $50 \%$ of the measurement variance. The Rho coefficients displayed in Table 4 indicate that the construct variances account for $85 \%$ to $90 \%$ of measurement variances.

The final reliability assessment method utilized is the average extracted variance (AEV). An AEV value should be higher than 50\% (Rivard \& Huff, 1988). The average extracted variance is the variance shared between a construct and its measures. The variance shared between the different constructs is the squared correlations between the constructs. As can be noted in Table 4, the AEV values for all the variables are higher than $50 \%$.

These criteria provide a critical evaluation of the measures and indicate that none of the items should be removed from further statistical analysis.

Table 4: Reliability Assessment

\begin{tabular}{lcccc}
\hline \multicolumn{1}{c}{ Variables } & $\begin{array}{c}\text { \# of } \\
\text { items }\end{array}$ & $\begin{array}{c}\text { Cronbach's } \\
\text { Alpha }\end{array}$ & Rho & AEV \\
\hline Team Building & 4 & 0.74 & 0.87 & 0.62 \\
Task Cohesion & 4 & 0.90 & 0.90 & 0.78 \\
Social Cohesion & 4 & 0.84 & 0.87 & 0.62 \\
Group Performance & 3 & 0.81 & 0.85 & 0.86 \\
\hline
\end{tabular}

\section{Convergent and Discriminant Validity Assessment}

Convergent validity can be assessed by the degree of "agreement" among items measuring the construct. To evaluate discriminant validity, Fornell and Larcker (1981) suggest a comparison between the average extracted variance of each factor and the variance shared between the constructs (the squared correlations between the constructs).

PLS was used to compute the covariance matrices of all measures used to evaluate the loadings of the different measures on their constructs. Table 5 reflects the loadings of items on their own constructs. It is expected that the loadings of all variables within the same construct should be high on this construct, indicating high convergent validity, and low on the others, displaying high discriminant validity. The first characteristic indicates that they share a lot of variance with their constructs, and the second that they are independent from the other constructs. These loadings 
show a clear discriminant and convergent validity for all constructs. Items show higher loadings on their respective variables indicating convergent validity and lower loadings on the other variables displaying discriminant validity.

Table 5: PLS loadings: Convergent and Discriminant Validity

\begin{tabular}{lcccc}
\multicolumn{5}{c}{ Loadings } \\
\hline TSK1 & $\begin{array}{c}\text { Task } \\
\text { Cohesion }\end{array}$ & $\begin{array}{c}\text { Social } \\
\text { Cohesion }\end{array}$ & $\begin{array}{c}\text { Group } \\
\text { Performance }\end{array}$ & $\begin{array}{c}\text { Team } \\
\text { Building }\end{array}$ \\
TSK2 & $\mathbf{0 . 8 5 7}$ & 0.125 & 0.693 & 0.415 \\
TSK3 & $\mathbf{0 . 9 1 8}$ & 0.173 & 0.779 & 0.482 \\
TSK4 & $\mathbf{0 . 8 7 4}$ & 0.113 & 0.617 & 0.394 \\
SOC1 & $\mathbf{0 . 7 1 1}$ & 0.456 & 0.558 & 0.802 \\
SOC2 & 0.351 & $\mathbf{0 . 7 8 9}$ & 0.325 & 0.614 \\
SOC3 & 0.052 & $\mathbf{0 . 8 0 3}$ & 0.066 & 0.528 \\
SOC4 & 0.250 & $\mathbf{0 . 8 5 7}$ & 0.096 & 0.610 \\
PRF1 & 0.101 & $\mathbf{0 . 7 1 1}$ & -0.005 & 0.300 \\
PRF2 & 0.665 & 0.117 & $\mathbf{0 . 9 0 6}$ & 0.403 \\
PRF3 & 0.774 & 0.278 & $\mathbf{0 . 9 4 0}$ & 0.536 \\
TMB1 & 0.763 & 0.118 & $\mathbf{0 . 9 4 4}$ & 0.458 \\
TMB2 & 0.208 & 0.286 & 0.133 & $\mathbf{0 . 7 4 9}$ \\
TMB3 & 0.695 & 0.555 & 0.560 & $\mathbf{0 . 8 7 4}$ \\
TMB4 & 0.164 & 0.476 & 0.103 & $\mathbf{0 . 7 4 2}$ \\
\hline
\end{tabular}

In Table 6, squared correlations are reported on the off-diagonal and AEV squared roots are reported on the on-diagonal. While the largest correlation (off-diagonal) is 0.62, the lowest AEV squared root (on-diagonal) is 0.79 . Hence, the smallest on-diagonal value is larger than largest off-diagonal values displaying the expected pattern. The results thus indicate that discriminant and convergent validity of the measures appear to be satisfactory. The measures can be used to assess the model further and to verify the hypotheses.

Table 6: Variance Shared Between Constructs

\begin{tabular}{lllll}
\hline \multicolumn{1}{c}{ Variables } & \multicolumn{4}{c}{ Variance } \\
\hline Task Cohesion & $\mathbf{0 . 8 8}$ & & & \\
Social Cohesion & 0.07 & $\mathbf{0 . 7 9}$ & & \\
Team Building & 0.40 & 0.46 & $\mathbf{0 . 7 9}$ & \\
Group Performance & 0.62 & 0.03 & 0.25 & $\mathbf{0 . 9 3}$ \\
\hline
\end{tabular}

\section{Assessment of the Structural Model}

The structural model shown in Figure 2 provides the hypothesized relationships between team building, task cohesion, social cohesion, and group performance. The constructs of the model are conceptualized with reflective items, since these items reflect their respective construct by co- 
varying simultaneously. Each hypothesis was tested using PLS Graph (Chin, 1995) and the path coefficients were observed. The estimated path effects are given along with their degree of significance. A bootstrapping procedure was used to assess the level of significance of the paths computed by PLS. T-values were computed from a series of PLS evaluations made against several partitions of the data set. The results of the PLS run with the overall sample ( $n=35$ groups) are shown in Figure 2.

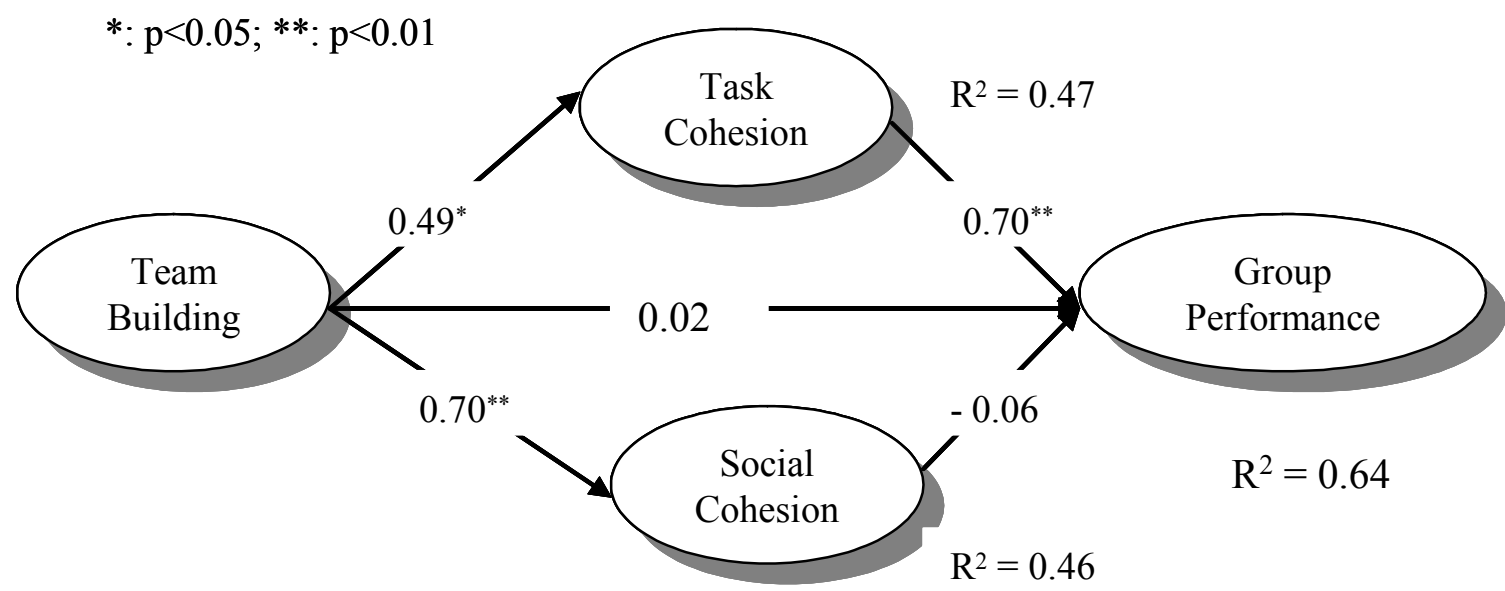

Figure 2: Parameters for the research model

Figure 2 presents the results of PLS analyses examining the hypothesized relationships between team building, task cohesion, social cohesion, and group performance. As can be seen in Figure 2, a very good overall fit was achieved for the model. The findings presented in Figure 2 and the hypotheses presented in Figure 1 are summarized in Table 7 for convenient comparison of the hypothesized and observed relationships.

Table 7: Summary of Parameters for the Research Model

\begin{tabular}{|c|l|c|c|l|}
\hline $\begin{array}{l}\text { Hypothe- } \\
\text { sis }\end{array}$ & Testing the relationship between & $\begin{array}{l}\text { Hypothesized } \\
\text { relationship }\end{array}$ & Result & $\begin{array}{l}\text { Significance } \\
\text { of the result }\end{array}$ \\
\hline H1a & Team building \& task cohesion & + & + & not significant \\
\hline H1b & Team building \& social cohesion & + & + & significant \\
\hline H1c & Team building \& group perform- & + & + & not significant \\
\hline H2 & Task cohesion \& group performance & + & + & significant \\
\hline H3 & Social cohesion \& group perform- & + & - & not significant \\
\hline
\end{tabular}

It should be noted that while a negative relationship was observed contrary to $\mathrm{H} 3$, it was not significant.

\section{Discussion and Conclusions}

The findings of this study provide support for the group-research theory perspective of group performance and some of its determinants. First, the study sheds light on the positive effect of team building on both task and social cohesion and non-significant and negligible effect of team build- 
ing on group performance. Group members who set objectives to achieve the group's goals, shared information regarding their respective roles within the group, were involved in the identification of major problems in the group and implemented solutions for those problems developed both task and social cohesion. This finding posits that the ever-present team-building ingredients will encourage group members to achieve a greater degree of task and social cohesion, but these results should be interpreted with caution. Prior research has found mixed results regarding the relationship between team building and group performance. While Shandler and Egan (1996) have found that there is a significant effect, Salas et al. (1999) found that $99 \%$ of the variability in a group's performance is attributable to factors other than whether the group had gone through a team building intervention. Our findings provide evidence that group cohesion fills this gap and plays an important intermediary role between team building and group performance.

The examination of the contributions of the two components of group cohesion yielded a very intriguing result: there was a significant positive impact of task cohesion on group performance, but no effect of social cohesion on group performance. For years, researchers studying group performance have searched for its antecedents. Mixed results on the effect of group cohesion on group performance are widely reported (Salas et al., 1999). We suggest that examining each component of group cohesion on group performance may yield a possible explanation of these

mixed results. Our results maintain that when a greater degree of task cohesion exists, groups will perform better. On the other hand, partying together and socializing among group members did not show any significant correlation with group performance. It is task cohesion that matters to performance and not social cohesion. Teams with a pre-specified set of goals and agenda for the project have the tendency to perform better than groups that only socialise. These results, however, should be interpreted with caution. To the best of our knowledge, this is the first study that tested this conceptualization of group cohesion and there may be a problem associated with the operationalisation and measurement of these two components. Further research is needs to confirm this observation.

In summary, the present results indicate that the research model built in this study provides insightful information as to some predictors of group performance, as well as the role played by task cohesion as an intermediary variable between team building and group performance. The results also suggest that the benefits group cohesion might exert on performance are likely to be seen in task cohesion and not social cohesion. In addition to distinguishing between the two dimensions of group cohesion and their role in assessing group performance, we also empirically tested a model based on group research theory, and related important antecedent constructs to group performance in IS project management setting. We clearly demonstrated that group cohesion, which was tested in prior research as a one-dimensional construct and the sole antecedent to group performance, to be a second order factor of two dimensions - social and task cohesion. Secondly, we demonstrated that task cohesion plays an important intermediary role between group performance and team building.

\section{Implications for Research and Practice}

For managers, this study illuminates the need to consider group cohesion, more particularly, task cohesion when various projects are assigned to systems development groups. Managers will obtain better results by grouping together individuals who show a higher degree of task cohesion. The practical literature on teamwork (Shea \& Guzzo, 1987; Trimmer, 1997) suggests that individuals who have undertaken team building development process have a high degree of task cohesion and our results confirm this observation. Also, our study suggests that managers need to pay special attention to team building because groups with a high degree of team building show a high degree of task cohesion and, hence, a higher performance. Taken together, these results sug- 
gest that, when considering developing software projects, managers can focus on improving group task cohesion rather than social cohesion to improve the team's performance.

For researchers, the findings of the study concur with existing studies and theory of group performance. While prior research has tested one-to-one relationships between constructs as shown in Table 1, our results demonstrate the value of the contributions of the antecedents and consequences of task and social cohesion. The integration of these constructs in one comprehensive model lays the foundation for future research concerning this important issue of group performance. Moreover, researchers interested in the issue of group performance will have a measurement instrument to operationalise these constructs.

\section{Limitations and Further Research}

Like other social science research, this study also has several limitations. First, using student subjects generates concerns about the generalizability of the results. There are ample examples of research in MIS that has relied on student subjects. A quick survey of MISQ and ISR since 2000, revealed 25 studies published using student subjects, some of which are Kim, Hahn, \& Hahn, 2000; Lim, Benbasat, \& Ward, 2000; and Palmer, 2002. Kim et al.'s (2000) study involved fourth year undergraduate students using multiple diagrams in object-oriented system development. They mention as a limitation that experts and professionals may behave differently. In Lim et al.'s (2000) study, undergraduate and graduate students evaluated the five-year performance of department heads using multimedia. In both studies while the students received brief training about the task during the experiment, they had no prior experience with it. And Palmer (2002) studied undergraduate, MBA and Executive MBA students evaluating corporate web sites. The relevance of the systems analysis task to the respondents who are fourth-year students majoring in MIS, may make it possible to generalize the findings to inexperienced systems analysts. Caution needs to be exercised, however, in generalizing the results to the entire systems analyst population. Professional and experienced system developers may exhibit characteristics based on their prior experience with software development projects that may be different than those of inexperienced systems analysts in this study.

Secondly, the role of group cohesion in relation to group performance was examined in a single snapshot survey. Future research could employ a longitudinal design in order to determine whether our results can be replicated. That is, instead of performing cross-sectional survey, one might follow the life cycle of groups to study how the relative influence of group cohesion changes over time. Another longitudinal study could involve tracking selected individuals as members of different teams and attempting to measure changes in their interactions and the effect on group performance. It would be interesting to observe if all teams they belong to are equally productive or if individual participants make a difference and if so to what extent

Lastly, the research group theory used in this study predicts relationships between the constructs studied. PLS analysis provides strong support for this interpretation since all of the relationships are tested simultaneously. However, conclusive statements about causality cannot be made since alternative explanations cannot be ruled out.

What we have observed in our research should be recognized as an early stage of theory building process. Our objective was not to determine all the antecedents of group performance. Rather, our primary intention was to examine group cohesion antecedent and its relation to group performance in one comprehensive model instead of one-to-one relationships. The current study sheds light on this initial nomoligical modeling process. 


\section{References}

Alavi, M., Wheeler, B. \& Valacich, J. (1995). Using IT to reengineer business: An explanatory investigation of collaborative telelearning. MIS Quarterly, 19(3), 293-312.

Bandura, A. (1997). Self-efficacy: The exercise of control. New York: Freeman.

Beer, M. (1976). The technology of organization development. In M. D. Dunnette (Ed.), Handbook of industrial and organizational psychology (pp. 937-994). Chicago: Rand McNally.

Carless, S. \& De Paola, C. (2000). The measurement of cohesion in work groups. Small Group Research, 31(1), 71-88.

Carmines, E. \& Zeller, R. (1979). Reliability and validity assessment, Iowa City, IA: Sage Publications.

Chang, A. \& Bordia, P. (2001). A multidimensional approach to the group cohesion-group performance relationship. Small Group Research, 32(4), 379-405.

Churchill, G. A. (1979). A paradigm for developing better measures of marketing constructs. Journal of Marketing Research, 16, 64-73.

Cohen, S. \& Bailey, E. (1997). What makes groups work: Group effectiveness research from the shop floor to the executive suite. Journal of Management, 23, 239-290.

Cota, A., Evans, C., Dion, K., Kilik, L. \& Longman, R. (1995). The structure of group cohesion. Personality and Social Psychology Bulletin, 21, 572-580.

Earley, C. (1994). Explorations of the individual and the collective self: Sources of self-efficacy across cultures. Administrative Science Quarterly, 39, 89-117.

Festinger, L., Schachter, S. \& Back, K. (1950). Social pressure in informal groups. New York, NY: Harper \& Row.

Ford, M. \& Morice, J. (2003). How fair are group assignments? A survey of students and faculty and a modest proposal. Journal of Information Technology Education. 2, 367-378.

Fornell, C. \& Larcker, D. (1981). Structural equation models with unobserved variables and measurement error. Journal of Marketing Research, 18, 39-50.

Forsyth, D. (1990). Group dynamics. Needham Heights, MA: Allyn \& Bacon.

Gackowski, Z. J. (2003). Case/real-life problem-based learning with information system projects. Journal of Information Technology Education. 2, 357-365.

Gibson, C. (1999). Do they believe they can? Group efficiency and group effectiveness across tasks and cultures. Academy of Management Journal, 42, 138-152.

Gibson, C., Randel, A. \& Earley, P. C. (2000). Understanding group efficacy: An empirical test of multiple assessment methods. Group \& Organization Management, 25(1), 67-97.

Gorla, N, \& Lam, Y. W. (2004). Who should work with whom? Building effective software project teams. Communication of the ACM. 47(6), 79-82.

Hackman, R. (1990). Groups that work (and those that don't): Creating conditions for effective teamwork. San Francisco: Jossey-Bass.

Hair, F., Anderson, R., Tatham, R. \& Black, W. (1998). Multivariate data analysis with readings. Englewood Cliffs, NJ: Prentice Hall.

Hardy, J. \& Crace, K. (1997). Foundations of team building: Introduction to the team building primer. Journal of Applied Sport Psychology, 9, 1-10.

Janz, B. (1999). Self-directed groups in IS: Correlates for improved systems development work outcomes. Information \& Management, 35(3), 171-192.

Jiang, J., Klein, G. \& Discenza, R. (2000). Pre-project partnering impact on an information system project, project team and project manager. European Journal of Information Systems, 11, 86-97. 
Kim. J., Hahn, J. \& Hahn, H. (2000). How do we understand a system with (so) many diagrams? Cognitive integration processes in diagrammatic reasoning. Information Systems Research, 11(3), 284-303.

Klein, H. J. \& Mulvey, P. W. (1995). Two investigations of the relationships among group goals, goal commitment, cohesion, and performance. Organizational Behaviour and Human Decision Processes, 61, 44-53.

Lee, C. \& Farh, J-L (2004). Joint effects of Group Efficacy and gender diversity on group cohesion and performance. Applied Psychology: An International Review, 53(1), 136-154.

Lim, K., Benbasat, I. \& Ward, L. (2000). The role of multimedia in changing first impression bias. Information Systems Research, 11(2), 115-136.

Mullen, B. \& Copper, C. (1994). The relation between group cohesion and performance: An integration. Psychological Bulletin, 115, 210-227.

Nunnally, J. C. (1978). Psychometric theory. McGraw-Hill, NY.

Palmer, J. (2002). Web site usability, design, and performance metrics. Information Systems Research, $13(2), 151-167$.

Pescosolido, A. (2001). Informal leaders and the development of group efficacy. Small Group Research, $32(1), 74-93$.

Peterson, E., Mitchell, T., Thompson, L. \& Burr, R. (1996). Group efficacy and shared cognition as predictors of group process and performance. Academy of Management Meetings, Cincinnati, $\mathrm{OH}$.

Phan, D., Vogel, D. \& Nunamaker, F. (1995). Empirical studies in software development projects: Field survey and OS/400 study. Information \& Management, 28(4), 271-280.

Podsakoff, P., MacKenzie, S. \& Ahearne, M. (1997). Moderating effects of goal acceptance on the relationship between group cohesion and productivity. Journal of Applied Psychology, 82(6), 974-983.

Powel, A., Piccolo, G. \& Ives, B. (2004). Virtual teams: a review of current literature and directions for future research. The Database for Advances in Information Systems. 35(1), 6-36.

Rivard, S. \& Huff, S. L. (May 1988). Factors of success for end-user computing. Communications of the $A C M, 31(5), 552-561$.

Salas, E., Rozell, D., Mullen, B. \& Driskell, J. (1999). The effect of team building on performance: An integration. Small Group Research, 30(3), 309-329.

Sawyer, S. (2004). Software development teams. Communications of the ACM. 47(12), 95-99.

Schafer, J. (2000). Analysis of incomplete multivariate data. Boca Raton, FL: Chapman \& Hall/CRC.

Shandler, M. \& Egan, M. (1996). VROOM! Turbo-charged team building. New York: American Management Association.

Shea, P. \& Guzzo, A. (1987). Group effectiveness: What really matters? Sloan Management Review, 28, 25-31.

Silver, S. \& Bufiano, M. (1996). The impact of group efficacy and group goals on group task performance. Small Group Research, 27, 55-72.

Smither, D., Houston, M., \& McIntire, A. (1996). Organizational development: Strategies for changing environments. New York, HarperCollins.

Spink, K. (1990). Group cohesion and collective efficacy of volleyball groups. Journal of Sport and Exercise Psychology, 12, 301-311.

Spink, K. \& Carron, A. (1993). The effects of team building on the adherence patterns of female exercise participants. Journal of Sport and Exercise Psychology, 15(1), 39-49.

Trimmer, K. (1997). Teamwork and information systems development effectiveness. Paper presented at the American Conference on Information Systems, Indianapolis, Indiana. 
Van Der Vyver, G. \& Lane, M. (2003). Using a team-based approach in an IS course: An empirical study. Journal of Information Technology Education. 2. 393-406.

Watley, J. (2004). An agent system to support student teams working online. Journal of Information Technology Education. 3, 54-63.

Widmeyer, N., L. Brawley, L., \& Carron, A. (1985). The measurement of cohesion in sports groups: The group environment questionnaire. London, Ontario, Canada: Sports Dynamics.

Woodman, W. \& Sherwood, J. (1980). The role of team development in organizational effectiveness: A critical review. Psychological Bulletin, 88, 166-186.

Yang, H.-L. \& Tang, J.-H. (2004). Team structure and team performance in IS development: A social network perspective. Information \& Management 41, 335-349.

Yoo, Y. \& Alavi, M. (2001). Media and group cohesion: Relative influences on social presence, task participation and group consensus. MIS Quarterly, 25(3), 371-390.

\section{Biographies}

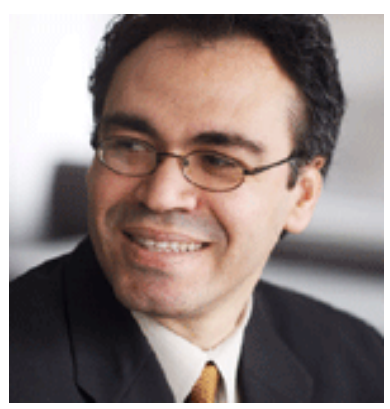

Bouchaïb Bahli is an assistant professor of Management Information Systems at John Molson School of Business at Concordia University. Dr. Bahli holds a Ph.D. from HEC-Montreal, University of Montreal. His research interests are in the areas of software project risk management, wireless computing, and outsourcing of information systems services. His work has been published in Communication of AIS, Journal of Information Technology, Information and Management, OMEGA, International Conference on Information Systems and Hawaii International Conference on Systems Science.

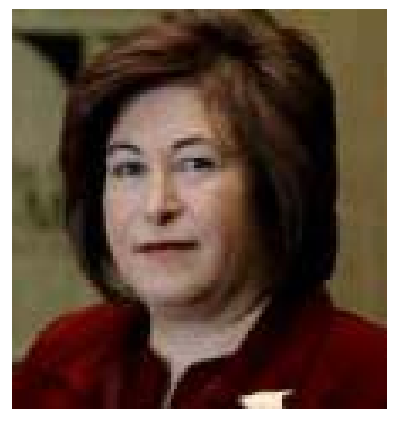

Meral Demirbağ Büyükkurt is an associate professor of Management Information Systems at John Molson School of Business at Concordia University. Dr. Buyukkurt holds a Ph.D. in Business with a major in Decision Sciences and minors in M.I.S. and Statistics from Indiana University. Her research interests are in the areas of information system development including teamwork among systems analysts, user requirements analysis and end-user computing. Her work has been published in Decision Sciences, Canadian Journal of Administrative Sciences, International Journal of Production Economics and Journal of Marketing Research. 